\title{
IDENTIFIKASI KESULITAN GURU PKn SMA di WILAYAH KECAMATAN SAWAHAN KOTA SURABAYA DALAM MENGIMPLEMENTASIKAN STRATEGI PEMBELAJARAN INOVATIF

\author{
Suhartono
}

Pendidikan Pancasila dan Kewarganegaraan, Fakultas Keguruan Ilmu Pendidikan, Universitas PGRI Adi Buana Surabaya suhartono@unipasby.ac.id

\begin{abstract}
Citizenship or Civics Education is a subject that is expected to shape the attitude and character of students. Learning activities in the classroom is not always fun. Teachers have difficulty in delivery of civic education materials to students. Civics teachers in the delivery of materials more commonly used conventional methods that lecture. As a result, the use of such methods only position students to be quiet, listen, take notes, and memorize. So with the policy of the use of innovative teaching strategies in the delivery of civic education materials are expected to assist students in understanding the material. Various types of innovative learning strategis such as Quantum Learning Strategies, Learning Strategies Inquiry, Problem Based Learning Strategies, Cooperative Learning Strategies, Contextual Learning Strategies, and Active Learning Strategies to provide facilities or provide a solution to the difficulties of the teacher in the classroom when the delivery of material.Methods of data collection in this thesis is that the questionnaire method is the main method in the research and documentation methods are used as a method to support in this study. Research is Education Departmen Sawahan. The data analysis technique used is descriptive statistical analysis techniques with the percentage.From the data analysis it can be concluded that the majority of high school Civics teacher in Sawahan district City of Surabaya have difficulties in implementing innovative learning strategies.
\end{abstract}

Keywords: Teacher Difficulties, Civics, Innovative Learning Strategies.

\section{PENDAHULUAN}

Selama ini kegiatan pembelajaran PKn banyak yang masih menggunakan metode ceramah. Peranan siswa di dalam kegiatan pembelajaran tidak terlalu banyak dan kebanyakan hanya mendengar penjelasan guru. Metode konvensional masih sering digunakan dalam pembelajaran PKn yaitu metode ceramah. Akibatnya siswa kesulitan memperoleh hasil belajar yang maksimal. praktik semacam itu membuat siswa kesulitan dalam pemahaman terhadap mata pelajaran PKn yang harapannya setelah pembelajaran siswa dapat menerapkan hasil belajarnya dalam implementasi kehidupan sehari-hari untuk menjadi warga negara yang baik. Berangkat dari permasalahan tersebut perlunya penerapan Strategi pembelajaran inovatif dalam pembelajaran mata pelajaran PKn di sekolah. harapannya dengan strategi pembelajaran inovatif tersebut bertujuan membantu siswa dalam memahami mata pelajaran PKn. Berbagai jenis strategi pembelajaran inovatif yang dapat guru gunakan saat kegiatan pembelajaran didalam kelas, misalnya seperti Strategi Pembelajaran Quantum, Strategi Pembelajaran Inkuiri, Strategi Pembelajaran Berbasis Masalah, Strategi Pembelajaran Kooperatif, Strategi Pembelajaran Kontekstual dan Strategi Pembelajaran Aktif. Berbagai jenis strategi pembelajaran inovatif tersebut memberikan kemudahan atau memberikan solusi mengenai kondisi kelas yang kurang kondusif saat di dalam kelas. Selain itu dari berbagai strategi tersebut guru dapat selalu berinovasi saat menyampaikan materi di dalam kelas. Menurut Hanifah (2009) menyatakan strategi pembelajaran yang digunakan guru dalam kelas sangat serta kaitannya dengan gaya belajar peserta didik 
(learning style) dan gaya mengajar guru (teaching style).

\section{METODE PENELITIAN}

Teknik memilih dan menentukan subjek penelitian dilakukan dengan menggunakan teknik Purposive Sampling (Subjek sesuai tujuan). Penentuan subjek penelitian dilakukan dengan tujuan meningkatkan informasi yang digunakan dari subjek yang kecil. Peneliti melakukan pemilihan subjek yang mempunyai pengetahuan dan informasi tentang fenomena yang sedang diteliti. Dalam penelitian ini peneliti memilih subjek penelitian guru PKn SMA di wilayah Kecamatan Sawahan Kota Surabaya. Adapun teknik pengumpulan yang di gunakan adalah angket dan dokumentasi. Angket digunakan untuk memperoleh data berdasarkan dengan pertanyaan penelitian yang sudah disusun, dan dokumentasi digunakan untuk memperoleh data jumlah SMA di wilayah Sawahan. Teknik Analisis Data menggunakan analisis statistik deskriptif kualitatif dengan rumus persentase. Waktu penelitian mulai tanggal 10 Juli sampai 14 Juli 2017, tempat penelitian di seluruh SMA, SMK, MA (Sederajat) di wilayah kecamatan Sawahan Kota Surabaya.

\section{HASIL PENELITIAN}

Hasil perhitungan data yang sudah diperoleh peneliti diketahui, (1) Dari data mengenai pemahaman guru-guru PKn SMA tentang Strategi Pembelajaran Inovatif menunjukkan $86,7 \%$ guru-guru mengetahui tentang strategi pembelajaran inovatif. (2) Guru yang sudah menerapkan strategi pembelajaran inovatif di kelas dalam pembelajaran PKn menunjukkan $66,7 \%$. (3) Tingkat kesulitan yang dialami para guruguru PKn dalam menerapkan strategi pembelajaran Inovatif sebanyak $80 \%$ (4) Guru PKn SMA dalam memperoleh sumber rujukan karena 46,7\% guru PKn menyatakan sumber informasi materi pembelajaran PKn diperoleh melalui buku paket. (5) Faktorfaktor yang mempengaruhi kesulitan guru PKn SMA diantaranya yakni 53,3\% guru menyatakan alokasi waktu yang tersedia cukup banyak. (6) Dalam hal sarana dan prasarana dalam mempengaruhi strategi pembelajaran PKn 53,3\% guru PKn SMA menyatakan sarana dan prasarana sangat membantu dalam penyampaian materi di dalam kelas. (7) Kegiatan pembelajaran yang selama ini sudah diterapkan $46,7 \%$ guru PKn SMA yakni hanya menggunakan media pembelajaran power point, (8) Sebanyak 46,7 $\%$ guru PKn SMA menggunakan metode konvensional/ceramah, karena proses pembelajaran banyak yang berusia rata-rata 50 tahun ke atas yang membuat mereka tidak sabar dalam penerapan strategi pembelajaran inovatif. Upaya yang dilakukan dalam menyelesaikan kesulitan guru PKn SMA dalam mengimplementasikan strategi pembelajaran inovatif yakni $100 \%$ guru PKn SMA dituntut dengan adanya kebijakan dari kepala sekolah untuk menggunakan strategi pembelajaran inovatif serta 33,3\% guru PKn SMA tersebut menyatakan dapat memahami dan menerapkan strategi pembelajaran inovatif melalui penataran.

\section{PEMBAHASAN}

Setelah dilakukannya perhitungan dengan teknik analisis statistik deskriptif kualitatif dengan rumus persentase diketahui bahwa ada guru PKn SMA di wilayah kecamatan Sawahan Kota Surabaya mengalami kesulitan dalam mengimplementasikan strategi pembelajaran inovatif. Temuan penelitian berdasarkan data yang telah diperoleh banyak kesulitan yang dialami guru dalam mengimplementasikan strategi pembelajaran inovatif yakni diantaranya mengenai sumber rujukan materi pembelajaran PKn SMA yang sangat minim diperoleh hanya melalui buku paket serta guru PKn SMA lebih cenderung menggunakan metode pembelajaran konvensional yakni ceramah. Padahal metode pembelajaran ceramah tidak efektif dan efisien untuk siswa dalam memahami materi pembelajaran PKn. Jika seorang guru dapat melakukan inovasi untuk menggunakan strategi pembelajaran inovatif dalam kelas saat memberikan materi pembelajaran PKn diharapkan tingkat pemahaman siswa tentang 
materi akan meningkat dan dapat terjadi interaksi siswa dan guru yang lebih efektif serta efisien.

\section{SIMPULAN DAN SARAN}

Sesuai dengan analisis data terhadap hasil penelitian, maka dapat disimpulkan bahwa terdapat kesulitan guru PKn SMA di wilayah kecamatan Sawahan Kota Surabaya dalam menerapkan strategi pembelajaran inovatif. Sekitar $86,7 \%$ guru mengetahui tentang strategi pembelajaran inovatif serta guru yang sudah menerapkan strategi pembelajaran inovatif dalam pembelajaran PKn di kelas menunjukkan 66,7\%. Kesulitan yang dialami $80 \%$ guru PKn SMA yakni dalam memperoleh sumber rujukan karena $46,7 \%$ guru PKn menyatakan sumber informasi materi pembelajaran PKn diperoleh melalui buku paket. Sehingga diharapkan Guru PKn SMA di wilayah Kecamatan Sawahan Kota Surabaya harus lebih meningkatkan pemahaman mengenai strategi pembelajaran inovatif agar dapat mengurangi atau mengatasi segala kesulitan dalam mengimplementasikan strategi pembelajaran inovatif dalam kegiatan pembelajaran di kelas. Jika guru PKn SMA di wilayah Kecamatan Sawahan Kota Surabaya memahami dan menerapkan strategi pembelajaran inovatif di dalam kelas dapat menarik perhatian siswa sehingga siswa dapat lebih interaktif lagi dalam pembelajaran PKn dan tidak bosan dengan penerapan strategi pembelajaran yang monoton seperti ceramah karena interaksi yang terjadi hanya satu arah. Upaya guru PKn SMA di wilayah Kecamatan Sawahan Kota Surabaya hendaknya tidak hanya di dukung dari kebijakan Kepala Sekolah untuk mengimplementasikan strategi pembelajaran inovatif namun kebijakan juga diwajibkan oleh Kepala Dinas Pendidikan wilayah Kecamatan Sawahan Kota Surabaya agar pembelajaran PKn di wilayah Kecamatan Sawahan dapat meningkat dan dapat membentuk karakter siswa lebih baik lagi.

\section{REFERENSI}

Amin, Z. 2008 Pendidikan Kewarganegaraan, Jakarta: Universitas Terbuka

Arikunto, S., 1993 Prosedur Penelitian, Jakarta, Rineka Cipta

Hadis, A., Nurhayati, B., 2010 Psikologi dalam Pendidikan, Bandung: Alfabeta

Hamruni. 2012 Strategi Pembelajaran, Yogyakarta: Insan Madani

Hanifah, N., Suhana, C. 2009 Konsep Strategi Pembelajaran, Bandung: Refika Aditama

Hendriono. Kemampuan Guru Mengatasi Kesulitan Belajar.

Iskandar. 2009 Metodologi Penelitian Kualitatif, Jakarta: Gaung Persada Press

Kaelan., Zubaidi, A. 2007 Pendidikan Kewarganegaraan, Yogyakarta: Paradigma. 